\title{
El papel de las redes migratorias en los procesos de reordenación de los flujos de bolivianos entre España y Brasil
}

\author{
Luisa Belchior Moskovics* \\ Paloma Moré Corral**
}

\section{Consideraciones metodologicas}

La metodología que hemos desarrollado se basa en una revisión bibliográfica exhaustiva de textos que abordan una comprensión histórica y sociológica de la migración boliviana, así como de datos estadísticos sobre las caracterísitcas de estos flujos. Además, se han realizado una serie de entrevistas en profundidad e informales tanto a emigrantes bolivianos como a personal de asociaciones y ONG y otros organismos relacionados con la asistencia, orientación y gestión de estos flujos. Una parte de estas entrevistas ha sido realizada en La Paz durante el mes de agosto de 2011, otra parte fue realizada en Madrid en los meses de octubre y noviembre y una última parte se ha realizado en São Paulo durante el mes de febrero de 2012. Estas entrevistas se han completado con varias sesiones de observación informal en barrios de concentración de población boliviana, tanto en Madrid como en São Paulo.

\section{Algunas consideraciones teóricas: redes y cultura migratoria}

Es sabido que los procesos migratorios son potenciados por la existencia de redes sociales, una forma específica de capital social que convierte la

\footnotetext{
* Periodista, Doctoranda en Migraciones Internacionales y Integración Social por el Instituto Universitário Ortega y Gasset, de Madrid.

** Socióloga, Doctoranda en Migraciones Internacionales y Integración Social por el Instituto Universitário Ortega y Gasset, de Madrid.
} 
migración internacional en una estrategia atractiva para la diversificación de riesgos o para maximizar posibles beneficios (MASSEY, 1998, p. 43). Las redes facilitan la migración, sirven de apoyo para encontrar trabajo, alojamiento, etc., y tienden a mantener los flujos entre determinados puntos geográficos y sociales. En el caso que estamos estudiando podemos distinguir diferentes redes migratorias, algunas tejidas durante décadas entre Bolivia y Brasil, concretamente la ciudad de São Paulo, y otras más recientes que han unido Bolivia, especialmente los núcleos de Cochabamba, Santa Cruz y La Paz, a España, principalmente Madrid y Barcelona.

Estas páginas pretenden ilustrar la idea de que la existencia de redes migratorias juega un papel importante en la ordenación de los flujos, pero que estos dependen a su vez de otra serie de factores tanto a nivel macro (coyuntura económica, políticas migratorias, etc.) como a nivel micro (decisiones individuales marcadas por presiones familiares, estrategias, etc.). Una cualidad especialmente útil de las redes es que son polivalentes, es decir, que sirven de apoyo para los migrantes en situaciones muy diversas. Del mismo modo que la red migratoria, a través de la reagrupación familiar, se ha convertido en única vía posible que los bolivianos pueden utilizar en estos momentos para emigrar a España, las redes migratorias establecidas entre el país andino y la ciudad de São Paulo están abriendo nuevas posibilidades en la estrategia migratoria de los retornados de España que han visto frustrados sus proyectos migratorios.

Por otra parte, consideramos que otro elemento teórico interesante para explicar los vínculos que unen las migraciones bolivianas a España y Brasil, pero también con Argentina, es la idea de causación acumulativa, es decir, que cada migración altera el contexto social en el que se produjo y por tanto, tiene consecuencias sobre los nuevos movimientos migratorios. Entre los distintos mecanismos sociales que pueden alimentar esa causación acumulativa nos parece especialmente interesante la idea de que a medida que aumentan las migraciones se genera cierta cultura migratoria que puede incentivar nuevos movimientos: "La satisfacción de las necesidades que originalmente motivaron la migración tiende a crear nuevas necesidades, $y$ la pobreza no se elimina con un solo viaje. Una vez que la migración ha sido experimentada, se convierte en un recurso familiar que puede ser empleado de nuevo si las necesidades vuelven a surjir. La migración altera los gustos y las expectativas lo que conduce a más viajes y a estancias más largas" (MASSEY, 1986, p. 671).

En el caso de Bolivia, además de las redes motivadas por las migraciones más recientes, se debe tener en cuenta que la cultura migratoria se ha forjado desde la época prehispánica debido a la constante movilidad que la población ejercía en busca de recursos (HINOJOSA, 2009a, p. 18). Bolivia es, por tanto, un país con una larga tradición de movilidad interna e internacional, la cual se ha quedado impresa en su cultura migratoria. 


\section{Bolivia como emisor de flujos migratorios hacia España}

Es difícil saber con exactitud las cifras a las que asciende la población emigrante en Bolivia pues según las fuentes se pueden encontrar datos que varían hasta en medio millón de personas (HINOJOSA, 2009b, p. 6). Sin embargo, según la Organización Internacional para las Migraciones, los emigrantes en Bolivia ascienden a 1,6 millones, lo cual representa el $16 \%$ de una población de 10 millones de ciudadanos (OIM, 2011).

Los destinos migratorios tradicionales de este país habían sido Argentina, Brasil y EEUU hasta que, a partir de la década del 2000, España empieza a aparecer como un destino atrayente para la población boliviana y, muy especialmente, para las mujeres. Es posible que la crisis económica y política que vivió Argentina en esos años haya contribuido a reorientar los flujos migratorios hacia España (SALAZAR, 2010, p. 90), un país que en esos momentos invertía su tendencia migratoria histórica gracias al factor de atracción que suponía la expansión de su mercado laboral.

Siempre trabajé (antes de ir a España), lo que pasa es que yo viví en Argentina y me vine de allá por la situación, por el corralito, vine para acá (a Bolivia) y estuve trabajando, estuve solamente un año y medio y como vi que no se ganaba, o sea, acá se gana para vivir, para comer y nada más." (...) "Nunca me imaginé irme a España, pero tenía una tía que vino y me dijo que se ganaba muy bien, que en un año se podía hacer mucho dinero y todo eso. Me decidí en una semana, saqué el pasaporte y me fui.

(Mujer procedente de Oruro, entrevistada en La Paz, agosto 2011).

La historia de la inmigración en España está marcada por la expansión del mercado laboral pues entre los años 1996-2006 se crearon cerca de siete millones de puestos de trabajo, siendo la tasa de crecimiento económico muy superior a la de la Unión Europea, representando un 54\% frente a un 13,7\% (ROCHA et al., 2008; CACHÓN y LAPARRA, 2009, p. 35). Así, como ya es sabido, España, un país de tradición emigrante, se convirtió de forma precipitada en el Estado que más población extranjera recibía dentro de la UE y en uno de los diez primeros países del mundo por el volumen de la población inmigrada, además de en uno de los principales países emisores de remesas del mundo (ARANGO, 2011, p. 54).

Desde entonces, la región andina ha sido una de las mayores proveedoras de migrantes y receptoras de remesas. Como puede verse en el Gráfico I, en 2007 el conjunto de habitantes de Bolivia, Colombia, Ecuador y Perú sumaban más de 1 millón y medio de residentes en España, un 60\% de la población total nacida en el extranjero (INE, 2011). 
Gráfico I. Población residente en España según país de nacimiento. Revisión del Padrón Municipal para cada año. Serie 2001-2011.

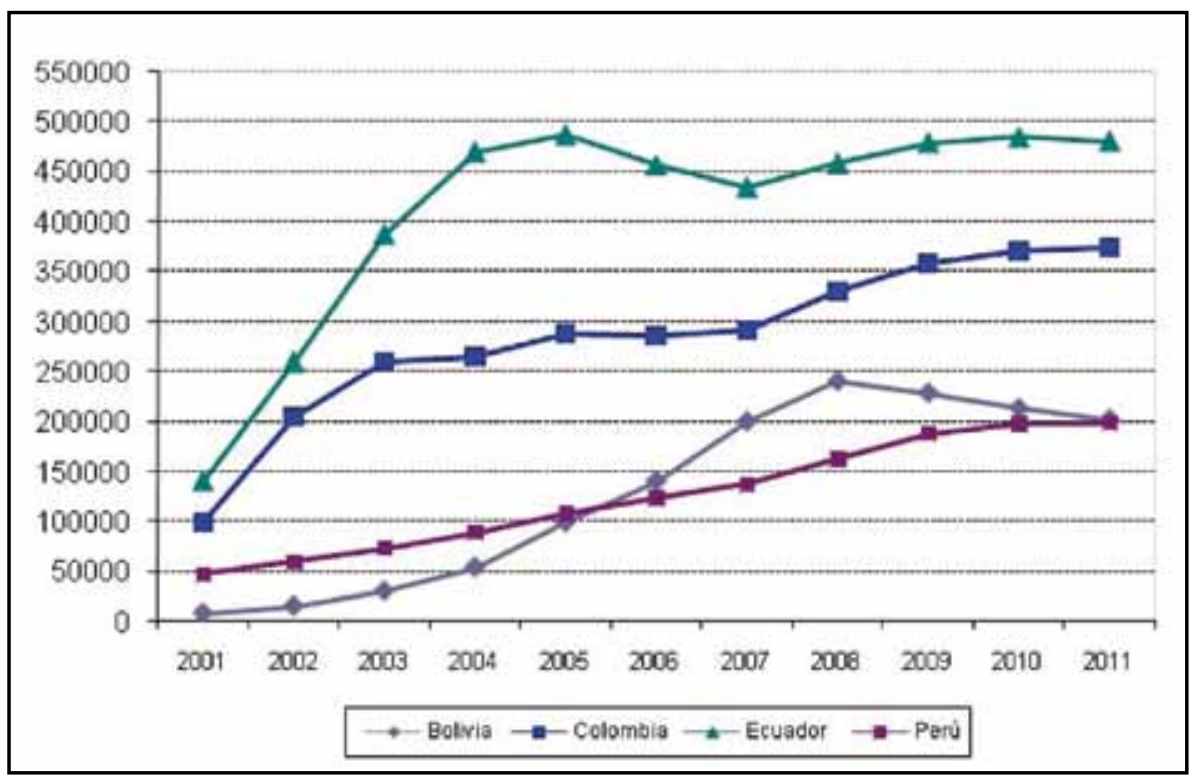

Fuente: Elaboración propia a partir de datos del Padrón Municipal de Habitantes. INE 2011.

En cuanto a la inmigración boliviana a España puede decirse que ésta ha experimentado dos fases bien diferenciadas, en un primer momento ha estado caracterizada por un éxodo masivo entre los años 2000 y 2008 y en un segundo momento, a partir del año 2008 , por un estancamiento y unos incipientes movimientos de retorno. La inserción laboral ha sido el leit motiv de esta emigración y por tanto la coyuntura del mercado de trabajo español ha sido el telón de fondo sobre el que se han llevado a cabo estos movimientos de población.

\section{Etapa de la "emigración masiva a España": 2000 - 2008}

Los primeros años del siglo XXI Bolivia estaba inmersa en un contexto de incertidumbre marcado por el descontento social y la inestabilidad política, factores que contribuían a bloquear las expectativas de ascenso social de muchos ciudadanos. En estas circunstancias la inexistencia del requisito de visado para entrar como turista en España era percibida como una gran oportunidad para dar el salto hacia Europa. Al mismo tiempo, eran los años dorados del crecimiento económico en España y el boca a boca funcionaba para difundir lo que no era ningún secreto: "allá se gana bien". Así comienza el periodo que podría denominarse como la "emigración masiva" hacia España. 
Según los datos del Padrón Municipal de Habitantes (INE) en 2001 residían en España poco más de 8.400 bolivianos, cifra que en 2005 ascendía a 100.000 y que en 2008 rondaría los 240.000. Durante estos años el incremento de bolivianos presentes en este registro ha sido muy intenso, especialmente en el periodo 2004-2008, como puede apreciarse en la Tabla I.

Tabla I. - Incrementos absolutos y relativos de población nacida en Bolivia (de nacionalidad boliviana y/o española) residente en España. Años 2001-2011.

\begin{tabular}{|l|l|l|l|l|l|l|l|l|l|l|}
\cline { 2 - 9 } \multicolumn{1}{c|}{} & $\begin{array}{l}2001- \\
02\end{array}$ & $\begin{array}{l}2002- \\
03\end{array}$ & $\begin{array}{l}2003- \\
04\end{array}$ & $\begin{array}{l}2004- \\
05\end{array}$ & $\begin{array}{l}2005- \\
06\end{array}$ & $\begin{array}{l}2006- \\
07\end{array}$ & $\begin{array}{l}2007- \\
08\end{array}$ & $\begin{array}{l}2008- \\
09\end{array}$ & $\begin{array}{l}2009- \\
10\end{array}$ & $\begin{array}{l}2010- \\
11\end{array}$ \\
\hline $\begin{array}{l}\text { Incre- } \\
\text { mentos } \\
\text { absolutos }\end{array}$ & 7.098 & 15.036 & 23.886 & 45.050 & 41.248 & 60.009 & 40.163 & -11.537 & -15.513 & -11.205 \\
\hline $\begin{array}{l}\text { Incre- } \\
\text { mentos } \\
\text { relativos }\end{array}$ & 84,28 & 96,88 & 78,17 & 82,75 & 41,46 & 42,64 & 20,01 & $-4,79$ & $-6,76$ & $-5,24$ \\
\hline
\end{tabular}

Fuente: Elaboración propia a partir de datos del Padrón Municipal de Habitantes. INE 2011.

Los rasgos que han caracterizado esta migración han sido la fuerte orientación laboral y su inserción precaria en el mercado de trabajo, la importancia de la presencia femenina y el origen localizado en el eje Cochabamba, Santa Cruz, La Paz. La mayor proporción de mujeres es una característica que ha sido distintiva de muchos colectivos latinoamericanos y que nunca ha dejado de ser un rasgo relevante del flujo de bolivianos. Como puede observarse en el Gráfico II la presencia de las mujeres se ha ido acentuando hasta el punto que en 2011 llegaron a representar el $58,4 \%$ del total de personas registradas en el Padrón (INE, 2011).

\section{Gráfico II. Bolivianos empadronados en España por sexo 2004-2011.}

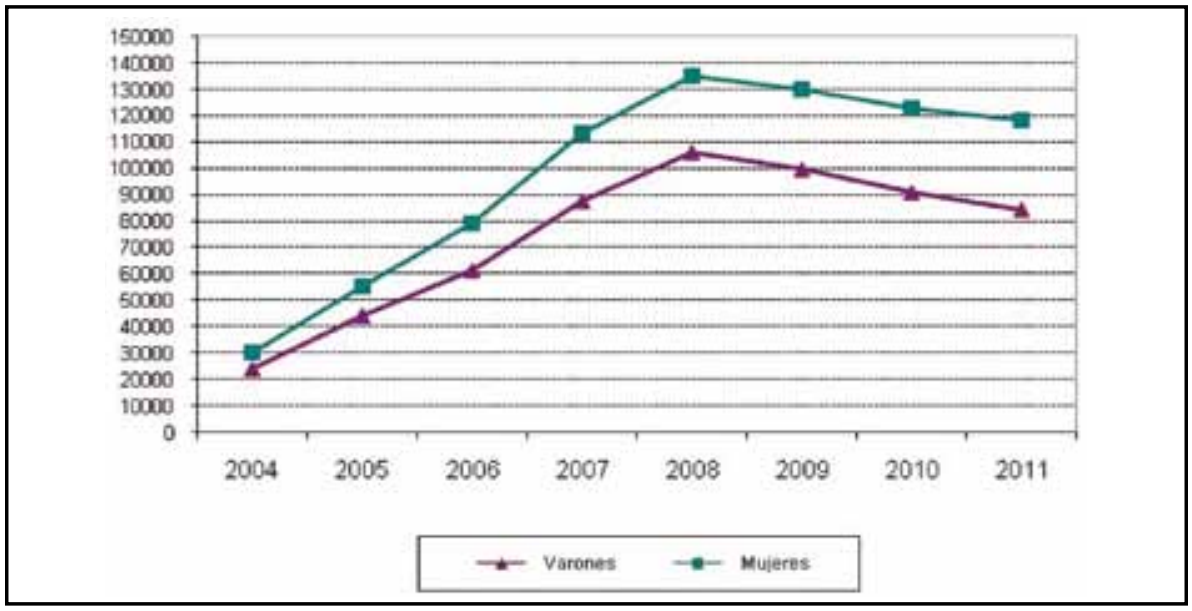

Fuente: Elaboración propia a partir de datos del Padrón Municipal de Habitantes. INE 2011. 
Una radiografía de las características de la población boliviana en España en los años previos a la crisis puede ser extraída del análisis de la Encuesta Nacional de Inmigrantes (ENI, 2007), el cual nos ofrece la imagen de una inmigración joven y volcada hacia el trabajo. La tasa de actividad reflejada en esta encuesta era excepcionalmente alta (91\%), incluso en comparación a otros migrantes andinos como los ecuatorianos (86\%), los peruanos y los colombianos (83\%). A su vez, las tasas de ocupación y de desempleo también eran comparativamente altas ( $81 \%$ y $10 \%$ respectivamente) (COLECTIVO IOÉ, 2010, p. 104-105). La alta proporción de activos se explica porque al ser un flujo de inmigración muy reciente apenas estaba formado por estudiantes o jubilados.

La precariedad y la inserción laboral en el sector secundario han sido los rasgos distintivos de la aventura laboral de los bolivianos en España. Mientras el 60\% de los varones encontraron su primer empleo en la construcción o la agricultura, el $73 \%$ de las mujeres se emplearon en el servicio doméstico, proporción superior a la de cualquier otro colectivo nacional (COLECTIVO IOÉ, 2010: p. 110 y 117). La inserción laboral en puestos que no requerían cualificación específica ( $80 \%$ en su primer empleo), los contratos temporales (91\%), las largas jornadas laborales (50,9 horas de media semanal) y los bajos salarios (una media de 1.000 euros para los varones y de 700 para las mujeres), mostraban al colectivo boliviano en una posición de mayor vulnerabilidad social que a los inmigrantes de otras procedencias (COLECTIVO IOÉ, 2010, p. 113-114).

Estas malas condiciones laborales pueden deberse a que el trabajo de campo de la encuesta se realizó en los años previos a la imposición del visado, cuando la mayoría de los bolivianos llegaban a España como turistas y cambiaban su estatus al de inmigrantes irregulares pasados tres meses. En esas circunstancias la incorporación al mercado laboral se realizaba en la mayoría de los casos a través del empleo sumergido. Este análisis concuerda con los datos recogidos por una encuesta realizada por ACOBE (Asociación de Cooperación Bolivia España) en 2007 según la cual el $82 \%$ de los bolivianos había entrado con visado de turista, el $62,5 \%$ estaba en situación irregular y el $72 \%$ estaba trabajando sin contrato de trabajo (ACOBE, 2007). En la Tabla II se ha intentado exponer una estimación, con todas las reservas metodológicas que esto pueda conllevar, de la proporción de personas bolivianas en situación irregular en dos momentos de la pasada década.

Tabla II. Estimación de la población irregular ${ }^{1}$ de bolivianos residentes en España.

\begin{tabular}{|l|l|l|l|l|l|}
\hline \multicolumn{3}{|c|}{$\mathbf{2 0 0 7}^{\mathbf{2}}$} & \multicolumn{3}{c|}{$\mathbf{2 0 1 0}^{\mathbf{3}}$} \\
\hline Empadronada4 $^{4}$ & Regular $^{5}$ & Irregular & Empadronada & Regular $^{\mathbf{6}}$ & Irregular $^{\mathbf{3}}$ \\
\hline 200.749 & 52.587 & 148.162 & 213.862 & 117.603 & 96.259 \\
\hline $100 \%$ & $26,20 \%$ & $73,80 \%$ & $100 \%$ & $54,99 \%$ & $45,01 \%$ \\
\hline
\end{tabular}

Fuente: Elaboración propia a partir de datos del Anuario Estadístico de Inmigración 2006 y 2009 y del Padrón Municipal de Habitantes 2007 y 2010. 


\section{El retroceso de la emigración a España: 2008 - 2012}

En 2008 se produce un punto de inflexión en esta tendencia migratoria, el cual está estrechamente vinculado a dos fenómenos relacionados con el contexto de recepción: la imposición del visado de turista y el estallido de la crisis económica en España.

En abril del año 2007 el Estado español impuso el requisito de tramitar un visado a aquellos ciudadanos bolivianos que deseasen viajar como turistas a España. Esta medida, motivada por el rápido aumento de los flujos en los años precedentes, produjo una ralentización de las entradas, al igual que había sucedido con otras nacionalidades años atrás. Ante la dificultad de cumplir los requisitos para acreditarse como turista, a partir de entonces, la vía más asequible y segura fue la tramitación de un permiso de trabajo aliada a una oferta previa. Según la Fundación Amibe-Codem, que presta servicios de asesoría jurídica en La Paz, desde abril de 2007 hubo un gran aumento de las consultas para tramitar visados de trabajo y estudios a partir de contratos emitidos desde España, en el caso de las mujeres, para ocupaciones de servicio doméstico, cuidado de ancianos y niños o auxiliares de geriatría, y para el caso de los hombres, en construcción y como técnicos electricistas.

Sin embargo, esta priorización de la inmigración regular vinculada al trabajo se vio truncada muy pronto debido al cambio en la coyuntura económica en España. En concreto por el vertiginoso aumento del desempleo, el cual motivó un repliegue en las opciones de entrada legal vinculada al empleo, además del endurecimiento de los controles a la inmigración irregular. Desde el comienzo de la crisis el "Catálogo de Ocupaciones de Difícil Cobertura" emitido por el INEM se ha visto notablemente reducido, lo que ha supuesto que los contratos en origen autorizados por la Delegación de Gobierno sean prácticamente imposibles de tramitar.

Muy poca gente es la que viene a consultar como se puede hacer un contrato de trabajo porque la gente es consciente de que por el tema de la crisis en España el tema de los contratos está prácticamente a cero. (...) En el 2010 es increíble la baja que ha habido en la demanda de asistencia para tramitar visados de turista o para los que tenían un contrato de trabajo en origen desde España. Ya en 2011 no atendemos prácticamente a nadie con visados de estudios y trabajo. En estos primeros seis meses habremos tenido unos cuatro o cinco visados de trabajo, nada más. Lo que sí hay bastante son las reagrupaciones, tanto en el Régimen General como en el Comunitario, cosa que antes no había.

(Encargada de la asesoría legal Amibe-Codem, La Paz, agosto 2011). 
Como ocurrió en los Estados centroeuropeos tras la crisis del petróleo de 1973 y la política de inmigración cero impuesta para poner fin al modelo "guestworker", se ha producido un aumento enorme de las demandas de reagrupación familiar. Esta vía constituye en la actualidad la única posibilidad realista que tienen los bolivianos para acceder a un permiso de residencia en España, debido a la contracción de las admisiones por motivos laborales.

El brutal ascenso del desempleo de los inmigrantes que se está produciendo desde el comienzo de la crisis, pero que se hizo mucho más dramático durante el año 2009 (OLIVER ALONSO, 2011, p. 132), es un factor a tener en cuenta en el reordenamiento de los flujos migratorios hacia España. En el caso de los bolivianos llama la atención que se trata del único colectivo de inmigrantes nacidos en los países andinos que está reduciendo su presencia en este país desde 2008 (ver Gráfico I). Esta excepción podría tener su explicación en que se trataba de un flujo más reciente y por tanto con menos asentamiento en el país de destino. Cuando empezó la crisis todavía había una alta proporción de personas bolivianas en situación irregular que no se habían podido beneficiar de los procesos de regularización colectiva (el último tuvo lugar en 2005) y que no habían cumplido aún el plazo de tres años de estancia acreditada en España para presentar el arraigo social.

\footnotetext{
Muchos de los que llegaron en el 2006 y 2007, en esa gran llegada masiva cuando se anunció que iba a imponerse el visado, no han logrado regularizar su situación. Entonces, esa gente que no ha logrado regularizar su situación está viviendo ahora justamente el impacto muy fuerte de la crisis, aparte del control constante de documentación que existe. Varios han sido retornados vía el $\mathrm{CIE}$, otros se han sumado a los programas de retorno voluntario y otros han retornado por su cuenta.

(Área de Investigación de Acobe y Fundación Codem, Madrid, octubre 2011).
}

En este contexto, el retorno voluntario se presenta a veces como parte de una estrategia para mejorar la situación, ya sea a través de los programas establecidos o gracias a los recursos propios. De los dos principales programas de retorno que existen en España ${ }^{7}$, el Programa de Abono Anticipado de Prestación a Extranjeros (APRE) y el Programa Retorno Humanitario o de Atención Social, los bolivianos han hecho uso generalmente del segundo ya que hasta $2011^{8}$ estuvieron excluidos del APRE debido a que Bolivia y España no habían firmado un acuerdo en materia de Seguridad Social. Aunque el convenio de colaboración se ha firmado en 2011, parece que por motivos sociológicos tampoco es un programa muy demandado entre los bolivianos:

Recién este año se ha firmado el convenio, pero de capitalización de paro no está habiendo mucha demanda 
porque los que están más con la mentalidad del retorno son las personas que están en situación irregular. La mayoría de los casos que se han atendido aquí son de vulnerabilidad social, que es gente que llevaba más de seis meses, incluso un año, dos, o tres años sin trabajar, con esa precariedad pero aparte con la imposibilidad de acceder a una tarjeta de arraigo social. Esos son los que llegan a un límite en el que la red social familiar que les apoyaba se desgasta y son los que se han sumado a los programas de retorno.

(Área de Investigación de Acobe y Fundación Codem, Madrid, octubre 2011).

Los motivos por los que se emprende el retorno son diversos y no existe un único perfil. Desde las personas que son expulsadas por estar en situación de irregularidad, hasta aquellas que optan voluntariamente por esa opción al no poder regularizarse o encontrar trabajo, pero también aquellas que deciden explorar nuevas posibilidades en el país de origen o las que regresan por motivos familiares y personales:

En el caso de las mujeres cuando deciden retornar no está tan vinculado a la falta de trabajo sino más vinculado a una situación familiar en el país de origen (...) como que ellas ven que aquí tienen más opciones. (...) Igual cuando son familias, se nota que la mujer lo siente más porque sabe que ella tiene más posibilidades de encontrar trabajo, aún sin tener papeles, aquí que en Bolivia.

(Área de Investigación de Acobe y Fundación Codem, Madrid, octubre 2011).

La inserción laboral en el país de origen tras el retorno es complicada y algunos pueden experimentar cierta sensación de frustración ante las expectativas no cumplidas. Para quienes se ven abocados a ello a través de una expulsión o para poner fin a una situación de precariedad es posible que el proyecto migratorio finalice de una manera prematura e inesperada sin que se hayan cumplido algunos de los objetivos que se habían planteado al inicio de la emigración. Para aquellos para los que el retorno es parte de una estrategia de movilidad social en el país de origen, es posible también que cuando vuelven lo que finalmente suceda no sea lo que esperaban:

Hay mucha gente que ha retornado con la esperanza de que habiendo ahorrado cierta cantidad de dinero iban a volver a su país, iban a implementar un negocio e iban a estar mucho mejor. Lamentablemente, en gran parte de los casos no es así, porque el nivel de vida aquí en Bolivia ha subido bastante, especialmente a partir de diciembre 
(2010), de lo que es el famoso gasolinazo ${ }^{9}$, el coste de las cosas se ha duplicado: bienes muebles, inmuebles, insumos domésticos, en todo, la canasta familiar, todo se ha duplicado. Entonces, si en su momento podíamos vivir con 1000 bolivianos, con un ingreso más o menos de ese monto, con un negocio de la persona que había retornado, pues ahora es el doble y ya no le abastece, entonces esa persona tiene el deseo y el interés de volver (a España). (...) Hay bastante gente con ese interés.

(Encargada de la asesoría legal Amibe-Codem, La Paz, agosto 2011).

En ambos casos, las dificultades administrativas para regresar a España, las redes migratorias consolidadas hacia países como Argentina y Brasil y los factores de atracción que se están generando en estos dos países limítrofes, pueden hacer aparecer la posibilidad de la re-migración como una opción atractiva para algunos:

No es casual de que exista ahora un incremento de la emigración al Brasil y muchos de los que están aquí van ya con esa mentalidad - "pues si no me va bien me voy a la Argentina o me voy a ir al Brasil" - entonces ya van con una mentalidad de - "si no me va bien no me voy a quedar allí (en Bolivia), me voy a ir a otro lugar".

(Área de Investigación de Acobe y Fundación Codem, Madrid, octubre 2011).

Bolivia, Brasil y Argentina son países que en demanda de retorno han subido muchísimo (desde 2007). Para el caso de Argentina y Brasil, por lo que nos cuentan algunos usuarios, influye mucho el hecho de que sean países que ahora mismo están desarrollándose más. Me comentaba una chica brasileña el otro día que ahora mismo con el tema de las Olimpiadas, el Mundial y todas las cosas que se van a hacer en los próximos años, se va a generar una demanda de trabajadores tremenda y hay mucha gente que está decidiendo volver (...) porque sabe que allí tiene muchas posibilidades y que su país le va a ofrecer mucho más de lo que le ofrece España, sobre todo en Argentina y en Brasil.

(Programa de Retorno Voluntario, ACCEM, Madrid, octubre 2011).

La confluencia de factores que están convirtiendo a Brasil en un país de atracción de flujos migratorios en la región y especialmente para la población boliviana es lo que vamos a intentar mostrar a continuación. 


\section{Foco hacia el sur: de España hacia Brasil}

Al analizar la inmigración reciente de bolivianos hacia Brasil debemos puntualizar que trataremos de los flujos hacia São Paulo, ya que es allí su principal destino dentro del país.

A pesar de que se haya intensificado con la crisis de 2008, se debe tener en cuenta que la migración de bolivianos a Brasil, sobretodo a la ciudad de São Paulo, ya era notable desde finales de la década de 1980, cuando comenzó una fuerte demanda de mano de obra subcontratada en el sector de la costura (SILVA, 2009, p. 5). La migración de este país hacia São Paulo ha estado muy conectada con el trabajo de la costura porque los talleres que ofrecían y todavía ofrecen productos a precios más bajos que el resto del mercado siempre han estado en manos de bolivianos, los cuales utilizan las redes para contratar a otros compatriotas.

Desde entonces, la mayoría de los que migran hacia São Paulo lo hacen ya con un puesto de trabajo garantizado en uno de los talleres (SILVA, 2009, p. 6). En todo el país, el sector de industria de transformación - en el cual se insertan los talleres de costura - absorben un $50,75 \%$ de los inmigrantes bolivianos (OIM, 2009).

Se trata, por lo tanto, de una migración fuertemente basada en las redes sociales establecidas entre los bolivianos ya emigrados y los que todavía lo desean hacer.

Así, antes mismo de la década de 1990, los bolivianos ya constituían el principal grupo de migrantes latinos en São Paulo. En la última década, pasaron a ser los más numerosos, junto a los peruanos, en todo el territorio brasileño (OIM, 2009, p. 22). El Censo de Brasil del año 2000 registra 20.288 bolivianos en el país (OIM, 2009, p. 31), pero se estima que, sólo en São Paulo, el número real es entre siete y diez veces el del registro del Censo, si se considera que hay todavía muchos bolivianos en situación irregular (BAENINGER y SOUCHAUD, 2007, p. 5). Ya el Ministerio de Justicia de Brasil, en datos recogidos en 2010, estima en 33 mil el número de extranjeros de esa nacionalidad en situación regular en el país.

La estimación de las cifras de la irregularidad de los bolivianos en Brasil es una tarea muy compleja, debido a que la mayoría trabaja dentro de talleres de costura donde el control de los contratos laborales es difícil. Sin embargo, la situación se ha estado transformando en la última década ya que, además del incremento del número de bolivianos en el país, el tema de las migraciones en Brasil ha empezado a entrar en la agenda política brasileña.

Es importante observar que Brasil no tenía fuertes olas migratorias desde el periodo entre el fin de la Segunda Guerra Mundial y los años setenta. Por ello, la legislación brasileña respecto a los extranjeros, que data de los años de la dictadura militar en el país, entre 1964 y mediados de los años ochenta, no se ha revisado hasta la fecha (Ley 6.815 de 19 de Agosto de 1980 que define la situación jurídica del extranjero en Brasil). Al tratarse de una ley confeccionada 
durante el período dictatorial, el texto muestra una marcada preocupación por la seguridad nacional y sostiene una mirada sospechosa hacia el inmigrante. Es decir, por la legislación actualmente vigente, el extranjero no tiene situación de igualdad con los ciudadanos nacionales en Brasil.

Desde 2009, el gobierno brasileño intenta aprobar en el Congreso una reforma de dicha ley que propondría la creación del Estatuto del Extranjero, flexibilizando las condiciones de entrada y permanencia de los inmigrantes en Brasil. Aún así el texto de la reforma todavía mantiene ciertas restricciones como es el caso de la posesión de tierras y propiedades.

Aunque el proyecto de reforma se encuentra actualmente estancado en el Congreso brasileño, el gobierno ha estado flexibilizando las condiciones de trabajo y residencia para los ciudadanos bolivianos. Desde los años 1980, hizo cuatro amnistías de las cuales los bolivianos fueron el mayor grupo beneficiario, sobretodo por el enfoque que medios de comunicación y órganos de defensa del pueblo empezaron a poner en condiciones de trabajo degradantes en los talleres de costura. En la última de ellas, en 2009 , los bolivianos constituyeron el $40 \%$ del total de los beneficiarios, según datos del Ministerio de Justicia de Brasil.

Otro factor, además de las amnistías y la crisis en los países europeos, ha estado facilitando la entrada de bolivianos en Brasil: los acuerdos firmados en los últimos años en el ámbito del Mercosur, por los cuales se establece la libre circulación de personas y la igualdad de derechos y condiciones de trabajo con los brasileños, incluyendo en ello, además de Argentina, Paraguay y Uruguay, a los ciudadanos de Bolívia y Chile.

Aparte de los flujos que ya se producían desde Bolívia hacia Brasil, la situación económica que se produjo en Brasil y en España desde la crisis económica de 2008 constituye uno de los factores clave para la hipótesis que se plantea en este trabajo. Mientras España ha tenido un decrecimiento del Producto Interno Bruto (PIB) y de puestos de trabajo desde 2008, Brasil, por otra parte, ha estado experimentando uno de los incrementos de economía más significativo en su historia democrática (IBGE, 2011).

De hecho, desde el año 2009, la entrada mensual de bolivianos que se dan de alta en el Consulado de Bolivia en São Paulo se incrementó un 20\%, según el vice-cónsul de Bolívia en São Paulo, Rolando Bulacios. Actualmente, el consulado registra cerca de 4.000 entradas mensuales.

En este panorama de factores push por parte de España y pull por parte de Brasil se dibuja la posibilidad de que un grupo cada vez mayor de bolivianos regresos de España por el deterioro del mercado laboral se dirija en dirección a Brasil. De hecho, aunque escasos, ya existen casos y relatos de ello. El consulado de Bolivia en São Paulo tiene este tipo de registro, a través de declaraciones informales, desde 2008, pero, según el vice-cónsul, Rolando Bulacios, ello se da de manera esporádica.

En un recorrido por las zonas de concentración de bolivianos en São Paulo, casi todos los entrevistados informales relataron conocer paisanos recién 
regresados de España con planes de irse a Brasil. Relatos como de Guillermo, boliviano que se prepara para ir a vivir a Brasil después de regresar a Bolívia de una estancia de ocho años en España, indican que la tendencia es creciente entre los que se ven obligados a regresar a su país pero no quieren terminar su trayectoria migratoria.

A nosotros nos cuesta volver a Bolívia porque por aquí no hay trabajo. Me cuentan mucho que en Brasil hay muchas oportunidades ahora mismo así que me parece una buena opción.

(Entrevista concedida por Guillermo Bermúdez por teléfono en febrero de 2012).

\section{Brasil y España: el Eldorado de los bolivianos}

Al contraponer el conjunto de testimonios recopilados para el presente artículo, se pudo notar que algunos bolivianos estaban proyectando hacia Brasil unas expectativas similares a que sus compatriotas habían elaborado con relación a España antes de la crisis económica de 2008. Esto se advierte sobre todo en bolivianos que dejaron España antes de la crisis o que nunca llegaron a emigrar y por tanto, tienen una visión más positiva de este país.

En un recorrido por el barrio del Bresser, en São Paulo, donde una comunidad de bolivianos se formó alrededor del consulado de su país, se nota todavía la curiosidad y admiración hacia España por parte de quienes migraron directamente a Brasil. En tres casos, entrevistados informales preguntaron sobre los trámites para entrar en el país y el coste de vida allí. Relataron que, en São Paulo, no pueden acceder a la situación financiera que deseaban y desde siempre han escuchado relatos de bonanza en el país europeo.

El caso de Lucía, que se marchó de España antes de la crisis, es emblemático. Ella vivió en España entre 1983 y 1986, donde trabajaba como empleada de hogar. Regresó a Bolívia porque tenia hijos en el país y con ellos se fue a Brasil, donde seguía hasta la redacción del presente artículo. Aunque cobre más en Brasil de lo que cobraba en España y que tenga una posición laboral mejor - es dueña de dos restaurantes en São Paulo -, Lucía afirmó que se vive mejor en España.

Para el futuro, lo mejor es vivir en España. Aquí en São Paulo hay menos prejuicio y son más amables. Pero Brasil es aún un país joven y hay mucho que desarrollar. Aquí todavía vienen los bolivianos por segunda opción, por no lograr ir a Estados Unidos o a España.

(Entrevista concedida en São Paulo, Brasil, febrero de 2012).

El discurso sobre las perspectivas de futuro cambia cuando se trata de entrevistados que estaban en España en la época de la crisis de 2008, como Milton, un joven boliviano que salió de Palma de Mallorca hacia São Paulo por la crisis. 
Se iba a España con muchas expectativas. Pero las condiciones que teníamos allí con la crisis destruyen todos nuestros sueños y planes. Hoy en día no veo manera de tener una buena vida allí. Trabajaba una, dos semanas en una construcción y luego me quedaba otras muchas más sin ningún trabajo. En Brasil no es tan mejor, pero por lo menos esta mucho más fácil de conseguir trabajo.

(Entrevista concedida en São Paulo, Brasil, febrero de 2012).

Las declaraciones sugieren que se está produciendo un cambio en la percepción de algunos ciudadanos bolivianos hacia lo que consideran el destino ideal para su proyecto migratorio. Mientras que hace unos años, España era considerada como Eldorado, en la actualidad esta imágenes idílica se ha quebrado y se puede estar desplazando hacia Brasil.

\section{Conclusiones}

La comunicación que hemos presentado no pretende ser un estudio cerrado ni ofrecer unas conclusiones firmes sino, que por el contrario, mostrar la existencia de un nuevo movimiento migratorio que puede tornarse en una tendencia creciente en los próximos años. Los datos y declaraciones que hemos recopilado para este trabajo parecen indicar que el desplazamiento de bolivianos hacia Brasil se está viendo alimentado por una coyuntura económica y política favorable, además de por la existencia previa de una sólida red migratoria. Al contrario, los factores coyunturales que ligan a la migración boliviana con España, están experimentando una tendencia opuesta, motivando el regreso de un número considerable de personas procedentes del país andino. Nuestro objetivo ha sido conectar estos dos fenómenos y a partir de ello sugerir la posible aparición de una conexión más amplia entre los tres países. Esta conexión podría incluso apuntar a una nueva tendencia migratoria que cuestionase las actuales, como es el retorno de un país del Norte hacia el Sur y la remigración hacia otro país del Sur, reconfigurando así el mapa de las migraciones internacionales.

\section{Notas}

1 - La estimación de la población irregular se ha hecho restando la población con permisos en vigor a la población empadronada. Las autoras reconocen los diversos límites de esta aproximación y la ofrecen simplemente como referencia estimativa.

2 - Los datos de autorizaciones y permisos de residencia corresponden a la fecha 31-12-06, mientras que los datos de empadronamiento son del 01-01-07.

3 - Los datos de autorizaciones y permisos de residencia corresponden a la fecha 31-12-09, mientras que los datos de empadronamiento son del 01-01-10.

4 - El dato de población empadronada se refiere a "nacidos en Bolivia".

5 - Este dato remite a las personas de "nacionalidad boliviana" con tarjeta o autorización de residencia en vigor a 31-12-06. Se ha incluido este dato al no estar disponible la información sobre "nacidos en Bolivia". 
6 - Este dato remite a los nacidos en Bolivia con certificado de registro o tarjeta de residencia en vigor a 31-12-09.

7 - Existe también un programa llamado Retorno Productivo, que concede asesoramiento y ayuda económica a las personas que presentan un proyecto empresarial en el país de origen. 8 - <http://www.tt.mtin.es/periodico/inmigracion/201110/INM20111025.htm>. Consultado el: 28 febrero 2012.

9 - El 26 de Diciembre de 2010 el Estado plurinacional de Bolivia promulgaba el decreto 748 con el fin de retirar la subvención sobre los hidrocarburos. Esta medida supuso un alza en el precio de la gasolina de entre el $70 \%$ y el $80 \%$.

\section{Referencias}

ACOBE. Situación General de los bolivianos en España. Un análisis cualitativo para obtener el perfil del colectivo boliviano con relación a las características del proceso migratorio. Madrid/La Paz, 2007.

ARANGO VILA-BELDA, Joaquín. Después del gran boom. La inmigración en la bisagra del cambio. En: ELISEO AJA, Fernández; ARANGO VILA BELDA, Joaquín y OLIVER ALONSO, josep (Dir.) Inmigración y crisis económica: impactos actuales y perspectivas de futuro. Anuario de la inmigración en España (edición 2010), 2011, p. 53-73.

BAENINGER, Rosana y SOUCHAUD, Sylvain. Vínculos entre a migração internacional e a migração interna: o caso dos bolivianos no Brasil. Brasília. Comisión Económica para América Latina y el Caribe (Celade), 2007.

CACHÓN, Lorenzo y LAPARRA, Manuel. Sistema migratorio, mercado de trabajo y régimen de bienestar: el nuevo modelo del sur de Europa. En: CACHÓN, Lorenzo y LAPARRA, Manuel (eds.). Inmigración y políticas sociales. Barcelona: Bellaterra, 2009.

COLECTIVO IOÉ y FERNÁNDEZ, Mercedes. Encuesta Nacional de Inmigrantes 2007: el mercado de trabajo y las redes sociales de los inmigrantes. En: Documentos del Observatorio, 2010.

ENI - ENCUESTA NACIONAL DE INMIGRANTES 2007. Disponible en: <http://www.ine.es/jaxi/ menu.do?type=pcaxis\&path=\%2Ft20\%2Fp319\&file=inebase \&L=0>. Consultado el: 24 febrero 2012.

HINOJOSA, Alfonso. Buscando la vida. Familias bolivianas transnacionales en España. La Paz: Clacso, 2009a.

HINOJOSA, Alfonso. Migracion transnacional y sus efectos en Bolivia. PIEB. 2009b.

IBGE (Instituto Brasileiro de Geografia e Estatística). Taxa de desocupação das pessoas de 10 anos ou mais nas regiões metropolitanas do Brasil, Rio de Janeiro/ São Paulo, 2011. Disponible en: <http://seriesestatisticas.ibge.gov.br/series.aspx?vcodigo=FDT0981\&t=taxade-desocupacao-das-pessoas-de-10-anos-ou-mais-de-idade-por-anos-de-estudo>. Consultado el: 14 febrero 2012.

INE. Encuesta de Población Activa, tercer trimestre de 2011. Madrid, 2011, p, 1. Disponible en: <http://www.ine.es/daco/daco42/daco4211/epapro0311.pdf> Consultado el: 18 febrero 2012.

MASSEY, Douglas S. The Settlement Process Among Mexican Migrants to the United States. American Sociological Review, vol. 51, no 5, p. 670-684, 1986.

MASSEY, Douglas et al. Contemporary theories of international migration. En: Worlds in motion. Understanding international migration at the end of the millennium, capítulo II. Oxford University Press, 1998.

OIM. Perfil Migratório do Brasil 2009. Disponible en: <http://publications.iom.int/bookstore/ free/Brazil_Profile2009.pdf>. Consultado el: 12 febrero 2012.

OIM. Bolívia Facts and Figures (2011). Disponible en: <http://www.iom.int/jahia/Jahia/ activities/americas/andean-countries/bolivia>. Consultado el: 24 febrero 2012.

OLIVER ALONSO, josep. El mercado de trabajo de la inmigración 2007-2010. Los cambios 
2009/2010 en el marco de la crisis. En: ELISEO AJA, Fernández; ARANGO VILA BELDA, Joaquín y OLIVER ALONSO, josep (Dir.) Inmigración y crisis económica: impactos actuales y perspectivas de futuro. Anuario de la inmigración en España (edición 2010), 2011, p. 130-164.

PORTES, Alejandro y BÖROÖCZ, Jozsef. Contemporary Immigration: Theoretical Perspectives on Its Determinants and Modes of Incorporation. En: International Migration Review, vol. 23, no 3, Special Silver Anniversary Issue: International Migration an Assessment for the 90's. (Autumn, 1989), p. 606-630, 1998.

ROCHA, Fernando; ARAGÓN, Jorge y CRUCES, Jesús. Cambios productivos y empleo en España. Ministerio de Trabajo e Inmigración: Madrid, 2008.

SALAZAR, Cecilia. La integración subordinada de las mujeres bolivianas en España. En: Migración, cuidado y sostenibilidad de la vida. La Paz: CIDES-UMSA, 2010.

SILVA, Carlos Freire da. Precisa-se: bolivianos na indústria de confecções em São Paulo. In: Travessia - Revista do Migrante, São Paulo, ano XXII, no 63, p. 5-11, jan./abr. 2009.

\title{
RESUMEN
}

Esta comunicación pretende relacionar dos tendencias migratorias de actualidad: el incipiente retorno de bolivianos que habían emigrado a España y la reactivación del flujo de inmigrantes de esta misma nacionalidad hacia Brasil. Nuestro objetivo consiste en analizar estos procesos desde las herramientas teóricas como son el concepto de redes migratorias, también llamada teoría del capital social, así como la idea de cultura migratoria.

Del mismo modo, discutimos la manera en que las transformaciones estructurales y coyunturales que están atravesando España y Brasil en los últimos años contribuyen a orientar los procesos de emigración que emprende la población boliviana. Entendemos que estos dos contextos de recepción están experimentando cambios sociales, políticos y económicos de muy distinta índole que pueden estar favoreciendo una reorientación de los flujos migratorios de la población boliviana.

A través del estudio de caso de la re-migración de bolivianos retornados de España, hacia Brasil, queremos destacar el dinamismo de los flujos migratorios, así como discutir la pertinencia de la denominación Sur-Norte y Sur-Sur en estos procesos.

Palabras clave: bolivianos; España; Brasil.

\begin{abstract}
This work puts in relation two migration trends of present time: the incipient return of Bolivians who had migrated to Spain in the past, back to their origin country and the reactivation of flows of citizens from Bolivia towards Brazil. Our goal consists in analyzing these two processes using some theoretical tools such as the concept of migration networks, also known as the social capital theory, as well as the migratory culture concept. Nonetheless, we put in discussion the way in which structural and short-term transformations in Brazil and Spain during last years help to orientate the migration processes that Bolivians are undertaking. We understand that these two reception contexts are going through some very different social, political and economical changes that may contribute to a reorganization of Bolivian migration flows. Through this case study of the re-migration of Bolivians returned from Spain, towards Brazil, we wish to point out migration dynamism, as well as discuss the pertinence of South-North and South-South denominations in these processes.
\end{abstract}

Keywords: bolivians; Spain; Brazil. 